\title{
Límites y desafíos de la Justicia Transicional en las nuevas transiciones: un análisis crítico a partir de los casos de Sierra Leona, Marruecos y Colombia
}

\author{
Farid Benavides, Oscar Mateos Martin y Blanca Camps Febrer*
}

\begin{abstract}
Resumen
La Justicia Transicional ha sido entendida como un campo de estudios que se encarga de analizar los mecanismos utilizados por las sociedades en transición para enfrentar el pasado. Los primeros análisis de Justicia Transicional abordaban la forma en la que las sociedades que transitaban de la dictadura a la democracia hacían frente a un pasado de violaciones de derechos humanos cometidas por agentes estatales. Dentro de esta visión de la Justicia Transicional, mecanismos de justicia penal, de verdad y de reparación constituían las bases de los estudios sobre las transiciones y los medios de hacer justicia. Sin embargo, este tipo de análisis fueron objeto de importantes críticas, tales como carecer de una visión distributiva, la poca atención que se ofrecía a problemas históricos y estructurales, el poco peso y protagonismo de los actores locales en el diseño e implementación de las diferentes medidas, el énfasis exagerado en la cuestión judicial y la poca atención a otros medios de hacer frente al pasado o bien la preeminencia de un enfoque liberal que daba por terminada la transición con superficiales cambios en el marco legal o institucional.

El presente artículo analiza algunas de las críticas realizadas, así como las diferentes propuestas planteadas, tales como la necesidad de centrarse en el carácter transformador de la justicia o en el uso de la justicia para hacer frente a la fase postconflicto, o bien en la necesidad de impulsar iniciativas basadas en el principio de apropiación local. Si en la primera parte se esboza un somero estado de la cuestión, la segunda parte del artículo tratará de analizar las experiencias de Sierra Leona y de Marruecos con el objetivo de avanzar algunos de los límites a los que se puede enfrentar Colombia en la implementación del Acuerdo de Paz.
\end{abstract}

Palabras clave

Justicia Transicional; paz liberal; Marruecos; Sierra Leona; Colombia.

TITLE

Limits and challenges of Transitional Justice in the new transitions: a critical analysis based on the cases of Sierra Leone, Morocco and Colombia

\begin{abstract}
Transitional Justice has been understood as a field of studies that analyzes the mechanisms that societies in transition use in order to deal with the past. The first analyses of Transitional Justice addressed the way in which societies transitioning from dictatorship to democracy faced a past of human rights violations committed by state agents. Within this vision of Transitional Justice, mechanisms of criminal justice, truth and reparation constituted the bases of studies on transitions and the means of doing justice. However, this type of analysis began to receive important critiques. Among the main criticisms were the lack of a distributive vision, or the little attention that was offered to historical and structural problems. It was also pointed out that local actors were given little weight and protagonism in the design and implementation of the different measures. Exaggerated emphasis was made in the judicial question while other means to face the past were given little attention. Finally, the pervasive liberal approach drove transitions to end up with superficial changes in the legal or institutional frameworks.

This article analyzes many of the critiques made, as well as the different proposals put forward, such as the need to focus on the transforming nature of justice; on the use of justice to deal with the post-conflict phase; or on the need to promote initiatives based on the principle of local ownership. A brief state of the art is outlined in the first part of the article. The second part of the article will try to analyze the cases of Sierra Leone and Morocco as imperfect models that might advance some of the limits that Colombia might phase in the implementation of the Peace Agreement.
\end{abstract}

* Farid BENAVIDES, profesor de la Facultad de Comunicación y RRII Blanquerna-URL y miembro del grupo de investigación GLOBALCODES.

Óscar MATEOS MARTIN, profesor de la Facultad de Comunicación y RRII BlanquernaURL y miembro del grupo de investigación GLOBALCODES.

Blanca CAMPS FEBRER,

doctoranda y profesora asociada en la Universidad Autónoma de Barcelona y colaboradora del grupo de investigación GLOBALCODES.

\section{Recibido:}

17-11-2017

Aceptado:

30-06-2018

\section{DOI:}

http://dx.doi.org/ 10.15366/relacionesinternacionales2018.38.006

\section{Keywords \\ Transitional Justice; liberal peace; Morocco; Sierra Leone; Colombia.}




\section{ntroducción}

La Justicia Transicional (JT) surgió hace más de dos décadas como resultado del análisis teórico de las transiciones a la democracia en el Cono Sur y en Europa del Este. Se trata de un campo académico y de un discurso que daba sentido a la aplicación de la justicia en tiempos de transición como parte de un cuerpo particular y específico de políticas públicas ${ }^{1}$. Paige Arthur ha elaborado una historia intelectual de la Justicia Transicional que muestra sus orígenes en las reuniones que se dieron en diversos lugares, promovidas por la Fundación Ford, y que pretendían que los y las diferentes activistas de derechos humanos de diferentes países compartieran sus experiencias de lucha contra la impunidad. Personas como Juan Méndez, José Zalaquett, Jaime Malamud y Diane Ohrentlicher, entre otras, contribuyeron a las reflexiones sobre la mejor manera de enfrentar un pasado de violaciones a los derechos humanos ${ }^{2}$.

Las activistas que participaron en esas reuniones perseguían que los Estados reconocieran la comisión de graves violaciones a los derechos humanos, repararan a las víctimas, transformaran los aparatos represivos del Estado y juzgaran y sancionaran a los responsables. Se llevaron a cabo los primeros juicios penales y con frecuencia el campo fue confundido con esta lucha contra la impunidad, entendida como ausencia de sanción penal ${ }^{3}$. Pero los juicios pronto generaron reacciones negativas y se produjo un cambio de políticas, en donde otro tipo de mecanismos fueron introducidos ${ }^{4}$. El balance de efectividad de la JT fue así relativizado e incluso su distinción con la justicia ordinaria y los dilemas a los que se enfrenta fue cuestionada ${ }^{5}$.

En paralelo, las medidas vinculadas a la JT fueron integrándose en las llamadas operaciones de construcción de paz posbélica, misiones que Naciones Unidas y otros actores internacionales empezaron a impulsar de manera especialmente intensa tras el fin de la guerra fría. Dichas operaciones contemplan el despliegue de iniciativas orientadas a abordar los diferentes aspectos relacionados con la reconstrucción de un país que ha padecido un conflicto violento. A la reforma del sector de la seguridad, el desarme, desmovilización y reconciliación de ex combatientes, la celebración de elecciones o a las políticas de liberalización de la economía, las operaciones de paz empezaron a integrar también medidas destinadas a impulsar la verdad, la justicia y la reparación de las víctimas de un conflicto armado. Como

1 Entendemos por campo un espacio de acción e influencia en el que confluyen diversas relaciones sociales. En el campo se dan ciertos habitus y se ejerce un capital social. También debe ser concebido como un espacio de luchas discursivas por la definición de un conjunto de prácticas. Ver BOURDIEU, Pierre, "Elementos para una sociología del campo jurídico" en BOURDIEU, Pierre y TEUBNER, Gunther, La fuerza del derecho, Universidad de los Andes, Bogotá, 2000.

2 ARTHUR, Paige, "How 'Transitions' Reshaped Human Rights: A Conceptual History of Transitional Justice" en Human Rights Quarterly, n³1, 2009, pp. 321 - 367.

3 FEIERSTEIN, Daniel, Juicios. Sobre la elaboración del genocidio, II, Fondo de Cultura Económica, Buenos Aires, 2015.

GONZALEZ-OCANTO, Ezequiel, Shifting Legal Visions: Judicial Change and Human Rights Trials in Latin America, Cambridge University Press, Cambridge, 2017.

LEWIS, Alison, "Confessions and the Stasi Files in PostCommunist Germany: The Modest Scales of Memory and Justice in Traitor to the Fatherland" en Australian Humanities Review, n059, 2016, pp. 209-222.

4 OLSEN, Tricia D. et al., Transitional Justice in Balance: Comparing Processes, Weighing Efficacy, United States Institute for Peace, Washington, 2010.

5 POSNER, Eric, y VERMEULE, Adrian, "Transitional Justice as Ordinary Justice" en Chicago Unbound, 2003, pp. 762 - 825. 
veremos, algunas de estas medidas tienen una naturaleza distinta $y$, en ocasiones, parten incluso de visiones contradictorias de la justicia.

La JT, así como el conjunto de las misiones de construcción de paz posbélica, ha sido sometida a diversas críticas. Algunas de estas han sido abordadas con éxito, otras solo han sido resueltas mediante la ampliación del campo, corriendo el riesgo de que todo sea JT y, por tanto, nada lo sea. En este texto pretendemos de manera breve ocuparnos de esas críticas y, a partir del análisis comparado de los casos de Sierra Leona, Marruecos y Colombia, dar cuenta de algunas de ellas. Para ello nos ocuparemos de analizar algunos de los textos seminales del campo, con el fin de mostrar sus intenciones originales. Asimismo, la selección de casos no es aleatoria. El análisis de Sierra Leona y de Marruecos, que pusieron en marcha las primeras medidas de JT a principios de los años 2000, arrojarán importantes luces que nos ayudarán a entender qué aspectos pueden ser relevantes para un contexto de JT mucho más reciente como es el de Colombia.

En este sentido, el artículo sostiene que, a la luz de los tres casos, la forma de entender la Justicia Transicional ha sido capturada por una visión liberal de construir la paz y de impulsar las transiciones, que ha acabado homogeneizando, estandarizando e institucionalizando su praxis. La JT así entendida no es más que una receta tipo one size fits all, en donde se repite, sin análisis del contexto o del conflicto, el mantra de justicia, verdad y reparación a partir de la aplicación de una serie de medidas. Asimismo, al tratar de responder a las críticas que se les hacen, los representantes de este modelo liberal de JT suelen reconocer los límites y suelen resolver las críticas incluyendo aquella carencia denunciada. De esta manera, la JT acaba siendo un concepto ambiguo que sirve tanto para aplicar medidas de justicia degradada como para implementar un populismo punitivo de los derechos humanos, esto es la apelación exclusiva al sistema penal para resolver los conflictos sociales ${ }^{6}$, en detrimento de una visión de la JT más restaurativa y centrada en las visiones y perspectivas locales. En los estudios de caso se muestra cómo la aplicación de esta caja de herramientas estándar no contribuye a la eliminación de las estructuras de impunidad y, por tanto, a garantizar la no repetición de los hechos violatorios de los derechos humanos ${ }^{7}$, ni tampoco a transformar las causas profundas del conflicto, sea social o armado.

\section{Del fetichismo de lo normativo al cinismo de lo pragmático: breve aproximación al concepto de Justicia Transicional}

\subsection{Antecedentes del concepto de JT}

Ruti Teitel, de la Escuela de Derecho de Nueva York, y Neil Kritz, del Instituto para la Paz de los Estados Unidos, introdujeron el término de Justicia Transicional (Transitional Justice) para analizar las diferentes prácticas de lucha contra la impunidad en las transiciones políticas de

6 GARGARELlA, Roberto, De la injusticia penal a la justicia social. Universidad de los Andes, Bogotá, 2008.

7 NESIAH, Vasuki, Transitional justice practice: looking back, moving forward. Research Report. Impunity Watch (May, 2016). Se puede alegar que ninguna sociedad ha logrado estas transformaciones y por ello es injusto 0 inadecuado cuestionar a la JT por esa falencia, como ya lo habían reconocido Vermeule y Posner. Pero el hecho es que uno de los reclamos de la JT radica precisamente en su intención de transformar la sociedad para lograr la no repetición de los hechos violatorios a los derechos humanos. 
las décadas de los ochenta y de los noventa8 ${ }^{8}$ No está claro quién utilizó el término por primera vez, pero sí lo es el hecho que en los análisis anteriores al texto de Teitel y a la colección de Kritz, no se utilizaba para referirse a las prácticas de hacer frente a los crímenes del pasado.

El texto de Kritz contribuye a crear el canon de la Justicia Transicional, inventando de esa manera una nueva tradición dentro del campo de los derechos humanos. En todo caso, es equivocado hablar, como lo hacen Teitel $^{9}$ y Elster $^{10}$, de un campo de JT con anterioridad al surgimiento del discurso que da coherencia y sentido a esas prácticas ${ }^{11}$.

El texto seminal de Kritz de 1995 es prologado por Nelson Mandela quien ubica la Justicia Transicional dentro del modelo de derechos humanos. Para Mandela, todos los países que han pasado por el trauma de violaciones masivas a los derechos humanos tienen que diseñar mecanismos no solo para hacer frente a esas violaciones del pasado sino para garantizar que la dignidad de las víctimas, de los sobrevivientes y de sus parientes sea restablecida. En la introducción de Kritz, Mandela llama la atención sobre la cuestión de la justicia y cómo algunos lo ven como la mejor manera de marcar una línea de diferencia entre el presente y el pasado en tanto otros lo ven como justicia de vencedores o justicia espectáculo ${ }^{12}$.

Por su parte Teitel, reconociendo el contexto intelectual del que provienen sus preocupaciones, analiza la cuestión del Estado de Derecho durante las transiciones. Para esta autora, comprender los problemas que se ocasionan por la justicia en un contexto de transición requiere analizar los dilemas que se presentan en estos periodos extraordinarios. La ley $-y$ el derecho- se ven atrapados entre el pasado y el futuro, entre una mirada retrospectiva y una prospectiva, entre lo individual y lo colectivo. Teitel acuña el término "transitional jurisprudence" que puede ser traducido como "teoría del derecho transicional" y afirma que dentro de un contexto de esta naturaleza el imperio de la ley debe ser entendido como un valor normativo que es histórica y políticamente contingente y que es elaborado en respuesta a la represión política en el pasado, con frecuencia perpetuada bajo el manto de la ley ${ }^{13}$. Con ello contribuye a fortalecer la idea de que la JT es una justicia de excepción que permite la moderación de los reclamos de justicia contenidos en las constituciones políticas. ${ }^{14}$

Arthur llama la atención respecto a la aceptación del término y, sobre todo, a la aceptación de la creación de un campo ${ }^{15}$. La mayor parte de las reseñas del libro de Kritz aceptaban su uso del término y en solo un caso hubo una crítica, por parte de Timothy Garton

8 TEITEL, Ruti, Transitional Justice. Oxford University Press, Oxford, 2000 y KRITZ, Neil (ed.), Transitional Justice. How emerging democracies reckon with former regimes, United States Institute for Peace, Washington, 1995.

9 TEITEL, Ruti, "Transitional Justice Genealogy" en Harvard Human Rights Journal, no 16, 2003, pp. 69 - 94.

${ }^{10}$ ELSTER, Jon, Closing the Books: Transitional Justice in Historical Perspective, Cambridge University Press, Cambridge, 2011.

${ }^{11}$ BOURDIEU, Pierre, Outline of a Theory of Practice, Cambridge University Press, Cambridge, 2005. FOUCAULT, Michel, Las palabras y las cosas. Una arqueología de las ciencias humanas, Siglo XXI, Madrid, 2006.

12 KRITZ, Neil (ed.), Transitional Justice...., op.cit.

13 TEITEL, Ruti, Transitional Justice.... op. cit.

${ }^{14}$ OROZCO ABAD, Iván, Justicia Transicional en tiempos del deber de memoria. Bogotá: Universidad de los Andes, 2009.

${ }^{15}$ ARTHUR, Paige, "How 'Transitions' ...", op.cit. 
Ash, a esa utilización del término Justicia Transicional ${ }^{16}$.

Ash reseñó el libro para la New York Review of Books e introdujo cuatro preguntas que son fundamentales para comprender la cuestión de la Justicia Transicional. Este autor se preguntaba si es necesario recordar el pasado o simplemente olvidarlo y mirar hacia el futuro; cuándo ocuparse del mismo; quién se encarga de ello; y cómo hacerlo. Tras un análisis de las diferentes alternativas se inclina por la historia y no por el derecho, pues son los historiadores quienes tienen los elementos para enfrentarse al pasado y para dar cuenta de él, sugiriendo incluso que el término Justicia Transicional fuera cambiado por el equivalente de las palabras alemanas Geschichtsaufarbeitung y Vergangenheitsbewältigung, que se podrían traducir como tratando el pasado, trabajándolo, confrontándolo, resistiéndolo, o enfrentándolo ${ }^{17}$.

Las iniciativas de Justicia Transicional han ido integrándose en las estrategias de construcción de paz posbélica, bajo la idea de que "no puede lograrse una verdadera paz sin justicia"18. Uno de los principales objetivos de las operaciones de construcción de paz posbélica, intensificadas desde mediados de los noventa, ha sido el de promover la recuperación psicosocial y la reconciliación entre las partes enfrentadas y transformar las actitudes y relaciones para que la violencia armada deje de ser considerada como una forma de resolver las incompatibilidades y disputas que pueden existir entre los diferentes grupos sociales y políticos ${ }^{19}$.

Naciones Unidas incorporó en el año 2004 la cuestión de la Justicia Transicional en sus políticas de construcción de paz y en ese año emitió un informe sobre la justicia y el Estado de Derecho. Posteriormente se ocupó del tema en el año 2012 asociándola con el fortalecimiento del Estado de Derecho, con lo que la impronta liberal de la JT quedó establecida ${ }^{20}$. Para dicha organización, la JT tiene que ver con los "procesos y mecanismos asociados con los intentos de una sociedad de esclarecer los abusos a gran escala realizados durante un conflicto violento, a fin de garantizar la rendición de cuentas, hacer justicia y lograr la reconciliación"21. Estos procesos implican mecanismos judiciales y no judiciales (con distintos niveles de participación internacional o ninguno en absoluto) tales como las indemnizaciones, la búsqueda de la verdad, reformas institucionales, investigaciones y despidos, o una combinación de todos estos.

En los últimos años, las experiencias de mayor trascendencia en contextos postconflicto han sido las "Comisiones para la Verdad y la Reconciliación" en Sudáfrica, Sierra Leona, Liberia, Perú o Guatemala o los "Tribunales especiales" en casos como los de la antigua región

${ }^{16}$ ASH, Timothy Garton, "The truth about dictatorship", The New York Review of Books (19 de febrero de 1998).

17 Ibídem, p. 332.

18 SRIRAM, Chandra Lekha. "Justice as Peace? Liberal Peacebuilding and Strategies of Transitional Justice", Global Society, Vol. 21, no 4, 2007, pp. 579-591.

19 DIEHL, Paul y Daniel DRUCKMAN. Evaluating Peace operations, Londres, Lynee Rienner Publishers, 2010.

${ }^{20} \mathrm{ONU}$, "El Estado de Derecho y la Justicia de Transición en las sociedades que sufren o han sufrido conflictos" Nueva York, S/2004/616.

ONU, "Informe del Relator de Naciones Unidas sobre la Promoción de la Verdad, la justicia, la reparación y las garantías de no repetición" A/2012/67/368.

${ }^{21} \mathrm{ONU}$, "Guidance note of the Secretary-General UN approach to Transitional Justice", 2010, p. 2. En: https:// www.un.org/ruleoflaw/files/TJ_Guidance_Note_March_2010FINAL.pdf. Consultado: 06-06-2018. 
de los Balcanes, la República Democrática del Congo o Camboya. Ambos instrumentos -que de manera excepcional y como veremos más tarde, fueron desplegados de manera casi simultánea en algunos contextos- ofrecen enfoques de reconciliación distintos. El primero apuesta por la reconciliación a través de la verdad, el diálogo y la reparación (justicia restaurativa), sin implicar necesariamente medidas punitivas; mientras que el segundo entiende la reconciliación a partir del castigo o la "retribución proporcional" hacia aquellos sujetos acusados de cometer determinados delitos durante la guerra (justicia retributiva) 22 .

Diversos Estados han implementado mecanismos para hacer frente al pasado, los cuales han sido calificados como de Justicia Transicional. Algunos casos también se han convertido en paradigmáticos y han sido objeto de exportación, generando lo que algunos autores han denominado la "industria de la Justicia Transicional"23. Hoy nos movemos en un campo que es muy diferente al de su surgimiento. El derecho ya no domina las discusiones, y las visiones pragmáticas son cada vez más centrales. Ello se ve en el reconocimiento de las amnistías, incluso para el caso de violaciones a los derechos humanos ${ }^{24}$.

\subsection{Problemas y límites del modelo liberal de Justicia Transicional}

La Justicia Transicional surge dentro del marco de la literatura sobre transiciones a la democracia. Eso hace que se den al menos siete problemas, analizados por diversos autores.

En primer lugar, la Justicia Transicional es el resultado de los análisis de la literatura sobre transiciones a la democracia, por lo que la base liberal del paradigma es clara, como lo es su limitación frente a las cuestiones estructurales. Asimismo, en los contextos postconflicto violento, la JT es considerada un instrumento más de un paquete de medidas más amplio que bebe esencialmente de una visión liberal de la paz que concibe la reconstrucción después de la guerra como una transición hacia la consolidación de los pilares del sistema liberal: economía de mercado y democracias multipartidistas.

En segundo lugar, resultado de esta limitación es la ausencia de preguntas sobre la justicia distributiva. Es cierto que las transiciones se dieron dentro de estados que formaban parte del Sistema Mundo capitalista y, por tanto, parece innecesario preguntarse por el cambio en lo económico. También es cierto que estas transiciones no cuestionaron el modelo económico, con la única salvedad de las del bloque soviético, pero en esos casos el tránsito fue hacia un modelo de economía capitalista. Pero, pese a ello, no hay preguntas acerca de las injusticias de clase o distributivas que dejó la transición. De hecho, uno de los principales límites atribuidos a las operaciones de construcción de paz posbélica es precisamente el impulsar una visión de paz negativa, muy restringida, que no aspira a una forma de paz positiva orientada a la erradicación de la violencia estructural. La apuesta, en algunos casos, por modelos punitivos de JT impediría que una visión más restaurativa haga aflorar

22 MALAN, Jannie. "Understanding Transitional Justice" en FRANCIS, David J. (ed.), Peace and conflict in Africa, Nueva York, Zed Books, 2010, pp. 133-147.

23 NAGY, Rosemary, "Transitional Justice as a Global Project" en Third World Quarterly, vol. 2, no 29, 2008 : 275 289.

${ }^{24}$ MALLINDER, Louise, Amnesty, Human Rights and Political Transitions: Bridging the Peace and Justice Divide, Hart, Londres, 2008. FREEMAN, Mark, Necessary Evils: Amnesties and the Search for Justice, Cambridge University Press, Cambridge, 2011. 
precisamente elementos distributivos y vinculados a la violencia estructural y a las injusticias sociales del contexto en cuestión. ${ }^{25}$

En tercer lugar, el primer modelo de JT fue uno de tipo normativo, con reclamos de lucha contra la impunidad. La introducción de una perspectiva descriptiva llevó a confundir lo simplemente descriptivo con lo prescriptivo, incurriendo en la falacia normativa de asumir que lo que es debe ser.

En cuarto lugar, los intentos de dar respuesta a estas preguntas llevan a lo que podemos llamar una transicionalización de la justicia ordinaria, o la indebida extensión del paradigma transicional.

En quinto lugar, se cuestiona, al menos en el análisis de algunos contextos, su inercia exógena, que impide tomar en consideración visiones locales de la paz, de la transición o de la reconciliación, marginando a menudo la dimensión social que apuesta por otra forma de hacer las paces o de reconstruir una sociedad devastada por la violencia de la guerra.

En sexto lugar, se cuestiona la incapacidad de la Justicia Transicional para dar cuenta de cuestiones estructurales como las exclusiones de raza y de género. ${ }^{26}$

Finalmente, se constata la aplicación del modelo de Justicia Transicional a casos sin transición, en donde la Justicia Transicional parece ser simplemente un pretexto para establecer políticas de impunidad, con lo que nos ubicamos en el otro extremo de la mirada original de la Justicia Transicional.

De manera reciente, también se ha señalado la responsabilidad de las empresas privadas en la vulneración de derechos y a la necesidad de incorporarlas y a los empresarios y a las empresarias como parte de la transición, ya sea como agentes o como sujetos objeto de investigación de juzgamiento. ${ }^{27}$

La identificación de estos problemas ha sido contrarrestada por algunos autores sugiriendo la ampliación del concepto de Justicia Transicional y recogiendo de esa manera el componente estructural que se les reclama. Desde esta perspectiva, se responde agregando cosas cada vez que se critica una carencia en el campo de la Justicia Transicional. Sin embargo, otros autores responden a esta visión sugiriendo que se limite el alcance del término, pues de

${ }^{25}$ Quienes abogan por un uso exclusivo de la justicia penal, olvidan los límites que también ésta presenta. Sobre ello ver el texto de D'Costa y sobre los juicios domésticos y sus posibilidades ver el artículo de Francesca Lessa. Esta última autora quiere mostrar que los juicios de Argentina son un caso particular de justicia por incluir delitos cometidos en varios países. Sin embargo, la autora tiene una visión muy limitada del derecho penal y pasa por alto el uso tradicional que se ha dado a la cooperación judicial para la investigación de delitos del crimen organizado en países como Colombia, Estados Unidos, España e Italia, entre otros.

${ }^{26}$ CESPEDEZ BAEZ, Lina María, Utopía u oportunidad fallida. Análisis crítico del acuerdo de paz. Bogotá: Universidad del Rosario, 2017 y CESPEDES BAEZ, Lina María, "Creole radical feminist transitional justice. An exploration of Colombian feminism in the context of armed conflict" en Fabio Andrés Díaz Pabón, Truth, Justice and Reconciliation in Colombia. Transitioning from Violence, Routlegde, Londres, 2018.

27 MICHALOWSKY, Sabine. Corporate accountability in the context of transitional justice, Routlegde, Londres, 2016. 
lo contrario termina perdiendo coherencia ${ }^{28}$. Para Sharp, concebir la Justicia Transicional como parte de una mirada de construcción de paz permite incorporar dimensiones no individuales de la justicia y responder a los reclamos de los $\operatorname{críticos}^{29}$.

Dube, por su parte, ha analizado la ausencia de relatos críticos de los efectos negativos en la Justicia Transicional ${ }^{30}$. La narrativa de la Justicia Transicional se caracteriza por concentrarse en las democracias recientes y con poca frecuencia se ocupa de casos de democracias consolidadas. El caso alemán se ubica en el contexto de sus dos transiciones, pero no en los retos actuales; y los casos de Estados Unidos y de Canadá se concentran en dos aspectos puntuales, pero no en las estructuras de exclusión existentes en esos países.

Así las cosas, debemos preguntarnos si tiene futuro la Justicia Transicional. O tal y como lo formula Makau Mutua, ¿es el vehículo de la Justicia Transicional un proyecto intelectual defendible, cuando se han señalado tantas limitaciones al mismo ${ }^{31}$.

\section{Sierra Leona y los límites del "modelo híbrido" de Justicia Transicional}

Sierra Leona ha sido uno de los principales "laboratorios" de las llamadas "operaciones de construcción de paz" de las que acabamos de hacer referencia. Desde la finalización de la guerra en 2002, centenares de reformas en diferentes ámbitos han sido diseñadas e implementadas por multitud de actores locales, regionales e internacionales, en lo que se ha concebido por la literatura más crítica como un modelo de construcción de paz claramente liberal, estandarizado y en el que las medidas de reconstrucción han sido desplegadas de arriba abajo con poca participación de los actores locales.

Una de las dimensiones más relevantes en el modelo de construcción de paz sierraleonés ha sido, precisamente, el de la Justicia Transicional, en el que han convivido de forma casi simultánea dos iniciativas de naturaleza distinta: la Comisión para la Verdad y la Reconciliación (CVR), una iniciativa de carácter restaurativo, y la del Tribunal Especial para Sierra Leona (TPSL), de carácter retributivo. El análisis del despliegue y coexistencia de ambas medidas dará cuenta ya de algunos de los límites que presentan las iniciativas de JT señalados anteriormente.

\section{1. ¿Una Comisión para impulsar la verdad y la reconciliación?}

La CVR fue creada por el acuerdo de paz de Lomé en julio de 1999. Dicho acuerdo contempló en aquel momento la amnistía de los combatientes que hubieran cometido crímenes entre el inicio del conflicto en marzo de 1991 y la firma del acuerdo de paz. La comunidad internacional, especialmente Naciones Unidas, mostró su preocupación por esta disposición, dado el nivel de

28 SHARP, Dustin, "Emancipating transitional justice from the bonds of the paradigmatic transition" en International Journal of Transitional Justice. Special Issue Transitional Justice. Does it have a future?, vol. 9, n 1, 2015, $\mathrm{p}$. 157. MCAULIFFE, Padraig, "Transitional justice's expanding empire: reasserting the value of the paradigmatic transition" en Journal of Conflictology, vol.2, n० 2, 2011, pp. 32-44.

${ }^{29}$ SHARP, Dustin, "Emancipating transitional...", op.cit., p. 160.

30 DUBE, Siphiwe Ignatius, "Transitional justice beyond the normative: towards a literary theory of political transitions" en International Journal of Transitional Justice, no 5, 2011, pp. 177-197.

31 MUTUA, Makau, "What is the future of transitional justice" en International Journal of Transitional Justice, no 9, 2015 , p. 2. 
violaciones de los derechos humanos que se habían producido. Para compensar este hecho, el acuerdo incorporó finalmente el establecimiento de una Comisión de Derechos Humanos y de una Comisión para la Verdad y la Reconciliación. El mandato de la Comisión, dirigida por el obispo metodista sierraleonés, Joseph Humper, era muy amplio y ambicioso, teniendo como objetivos principales: i) crear un documento imparcial que relatase las violaciones y abusos de los derechos humanos y del derecho humanitario internacional cometidas durante el conflicto armado; ii) hacer frente a la impunidad en el país y, iii) abordar las causas de fondo del conflicto para evitar la reanudación de la violencia y para afrontar las necesidades de las víctimas y promocionar la reconciliación. La Comisión también debía prestar especial atención a las experiencias de las víctimas de abusos sexuales y a los menores. Para hacer efectivo este mandato tan amplio, la CVR recibió un estatus independiente, recursos para contratar el personal necesario y un mandato de un año y medio que podía ser prolongado ${ }^{32}$.

La primera fase operacional de la Comisión consistió en la búsqueda de testimonios que quisieran hablar sobre lo sucedido durante el conflicto. Un total de 75 empleados de la CVR, todos sierraleoneses, fueron desplegados por todo el país. En cuatro meses lograron recoger más de 10.000 declaraciones de personas que habían sido víctimas, perpetradores o testigos de violaciones de los derechos humanos. Estas declaraciones fueron todas codificadas e introducidas en una base de datos que sirvió para que los investigadores de la Comisión (muchos de los cuales eran internacionales) pudieran contar y categorizar los diferentes tipos de violaciones ${ }^{33}$. La segunda fase de la Comisión contempló un proceso de escuchas públicas durante un período adicional de cinco meses en la que participaron un total de 450 personas. Aunque tanto menores como aquellas mujeres que habían padecido abusos sexuales tenían la posibilidad de declarar ante una cámara de manera anónima, la sorpresa para la Comisión fue que muchas de estas víctimas insistieron en declarar de forma pública, argumentando que querían que sus respectivas comunidades escucharan lo que les había sucedido y que fueran conscientes del estigma que les perseguía, así como de la identidad de los que habían sido sus perpetradores. En este sentido, la CVR permitía, siempre que esto fuera posible, que los individuos que eran nombrados por una víctima tuvieran el derecho a réplica ${ }^{34}$. Por lo que respecta a los menores, la Comisión decidió tomar declaración de forma individual para garantizar que sus experiencias eran incluidas en el informe final, hecho que fue criticado por algunas organizaciones como UNICEF al considerar que este proceso no hacía sino agravar los traumas de muchos de estos menores.

Tras meses de trabajo, la Comisión fue capaz de obtener una versión muy completa de lo que había sucedido durante la guerra, así como de las percepciones sociales respecto a cuáles habían sido las causas que habían provocado el estallido del conflicto armado. El resultado final fue un informe hecho público en octubre de 2004 de casi cinco mil páginas distribuidas en tres volúmenes diferentes: en el primer volumen se explicaba el mandato de la Comisión y la metodología utilizada; en el segundo volumen quedaban reflejadas las conclusiones y principales hallazgos, las recomendaciones, las reparaciones que debían

\footnotetext{
32 INTERNATIONAL CRISIS GROUP (ICG), Sierra Leone After Elections: Politics as Usual?, Africa Report, no 49, Freetown / Bruselas, 2002.

${ }_{3}^{3}$ DUGAL, Z., "Witness to Truth: the TRC of Sierra Leone - An Overview" en GBERIE, L. (ed.): Rescuing a Fragile State. Sierra Leone 2002-2008, Ontario, LCMSDS Press of Wilfrid Laurier University, 2009, pp. 30-31.

${ }^{34}$ DUGAL, Z., op.cit. p. 31
} 
llevarse a cabo, así como la lista total de víctimas; mientras que en el tercero (dividido en dos partes) se explicaban de manera detallada los antecedentes históricos, la naturaleza del conflicto y el papel de los diferentes actores (locales, internacionales, etc.) y principales grupos sociales afectados por el conflicto (niños, jóvenes y mujeres).

En cuanto a las recomendaciones, la Comisión distinguía entre varias categorías, señalando las que debían ser tomadas en consideración por el Gobierno y los actores internacionales, hasta aquellas que revestían un carácter urgente, como, por ejemplo: la lucha contra la corrupción, la protección de los derechos humanos, el establecimiento del imperio de la ley, la gestión de los recursos naturales o la mejora de la situación de los menores, las mujeres y los jóvenes. La reacción del Gobierno ante las recomendaciones sugeridas por la Comisión se plasmaron en el Libro Blanco que el Ejecutivo hizo público en junio de 2005, casi un año después de la publicación del informe de la CVR. Otro de los problemas señalados fue la constante falta de financiación que la CVR sufrió, lo que hizo peligrar en algunos momentos el desarrollo de sus funciones y la demora de la publicación del informe final ${ }^{35}$.

\subsection{El Tribunal Especial y el despliegue del modelo punitivo}

El Tribunal es una institución excepcional en el ámbito de la justicia internacional, diferente a sus antecesoras (el Tribunal Internacional para la Antigua Yugoslavia y el Tribunal Internacional para Ruanda) y con base en Freetown, capital de Sierra Leona ${ }^{36}$. El origen del Tribunal se encuentra también en los acuerdos de Lomé de 1999, aunque no de una forma tan explícita como la CVR. En la redacción final del acuerdo, Naciones Unidas logró incorporar en el texto una cláusula en la que se explicitaba la disconformidad de la organización con conceder el perdón y la amnistía a todos los combatientes y en la que se solicitaba el establecimiento futuro de un tribunal que juzgara los crímenes de guerra en el país. Esta petición cobró especial relevancia tras los incidentes de mayo de 2000 (secuestro de 500 cascos azules a manos del Revolutionary United Front, principal grupo armado durante la guerra) y una vez este último grupo fue desmantelado y su líder, Foday Sankoh, arrestado ${ }^{37}$. Fue entonces cuando el Presidente sierraleonés, Ahmed Tejan Kabbah, solicitó al Secretario General de Naciones Unidas, Koffi Annan, el establecimiento de un Tribunal que juzgara los crímenes de guerra o bien ampliar el mandato del Tribunal Especial para Ruanda a Sierra Leona. El embajador estadounidense ante Naciones Unidas, Richard Holbrooke, rechazó la última propuesta y presionó para el establecimiento de un Tribunal Especial. En agosto de 2000, el Consejo de Seguridad de Naciones Unidas aprobó una resolución instando al Secretario General a negociar con el Gobierno sierraleonés los términos del Tribunal.

En enero de 2002, Naciones Unidas y el Gobierno sierraleonés firmaban un acuerdo en el que se establecía oficialmente el Tribunal y dos meses más tarde el Parlamento sierraleonés aprobaba el Estatuto del Tribunal Especial de Sierra Leona. Dicho estatuto revocaba la ley de amnistía aprobada en Lomé y establecía la primacía del Tribunal por encima de los tribunales nacionales. El Tribunal Especial empezó poco después su trabajo, instituyendo tres órganos

\footnotetext{
35 DOUGHERTY, BETH K., "Searching for Answers: Sierra Leone's Truth y Reconciliation Commission", African Studies Quarterly, vol. 8, no 1, 2004, pp. 39-56.

${ }^{36}$ NO PEACE WITHOUT JUSTICE (NPWJ), "Lawyers' Guide to the Special Court for Sierra Leone", Freetown, 2004.

37 INTERNATIONAL CRISIS GROUP (ICG), "Sierra Leone: The State of Security and Governance", Africa Report, no 67, Bruselas, 2003, p. 2-3.
} 
principales: los Juzgados, la Oficina del Fiscal, y el Registro. Se nombraron ocho jueces, de distintos países, la mayoría de los cuales ya tenían experiencia en otros casos de juicios sobre crímenes contra la humanidad, mientras que los de nacionalidad sierraleonesa se caracterizaban por haber vivido durante mucho tiempo fuera del país.

La primera fase del Tribunal fue determinar por parte del Fiscal, David Crane, y su equipo quienes habían sido los "principales responsables de cometer violaciones de los derechos humanos". El 7 de marzo de 2003 Crane anunció la lista de acusados, comprendiendo un total de 13 personas $^{38}$. Algunas de estas imputaciones fueron recibidas con sorpresa e incluso con indignación por parte de algunos sectores de la población. Isa Sesay, uno de los acusados y líder interino del RUF tras el arresto de Sankoh, era considerado por muchos la persona dentro del grupo que verdaderamente había perseguido el desarme y había mostrado la voluntad de acabar con los enfrentamientos armados, por lo que no se acababa de entender que fuera considerado como uno de los principales perpetradores. Pero la imputación más polémica fue la de los tres miembros de las Civilian Defence Force (CDF), especialmente la de su líder, Hinga Norman, quien había sido Viceministro de Defensa en el primer Gobierno de Kabbah y que en el momento de la acusación era Ministro de Seguridad Interna. Su arresto despertó un gran rechazo entre las poblaciones del sur y del este, donde Norman y las CDF eran consideradas "héroes" que habían defendido a la población de los ataques del RUF durante muchos años. Estas críticas también señalaban el sesgo local que había adquirido el Tribunal al no contemplar las violaciones de derechos humanos provocadas por las tropas de mantenimiento de la paz, tanto del ECOMOG como de Naciones Unidas ${ }^{39}$.

El proceso a partir de entonces estuvo lleno de dificultades ${ }^{40}$. Los veredictos para las diez personas que finalmente fueron juzgadas se hicieron públicos tras largos juicios televisados y abiertos a los ciudadanos que quisieran estar presentes. Entre 2007 y 2008, la mayoría de los imputados fueron acusados de sus cargos y condenados a cumplir penas de entre 15 y 20 años (en los casos del CDF) hasta penas de entre 40 y 50 años (por lo que respecta a los casos del RUF y del AFRC). El Tribunal, clausurado oficialmente en 2009, implicó un gasto superior a los 200 millones de dólares, en comparación con los 6 millones que habían sido destinados para la CVR ${ }^{41}$.

\section{3. ¿Castigo sin reconciliación ni mejoras sociales?}

Los límites del modelo de Justicia Transicional sierraleonés son, en buena medida, los límites ampliamente criticados en los últimos años al modelo de construcción de paz liberal.

${ }^{38}$ Foday Sankoh, Sam Bockarie, Issa Sesay, Morris Kallon y Augustine Gbao (pertenecientes al RUF); Johny Paul Koroma, Alex Tamba Brima, Brima Bazzy Kamara y Santigie Borbor Kanu (del Armed Forces Revolutionary Council, AFRC); Hinga Norman, Moinana Fofana y Alieu Kondewa (de las Civilian Defence Force, CDF), y unos meses más tarde, el todavía Presidente liberiano, Charles Taylor.

39 PENFOLD, Peter, "The Special Court for Sierra Leone: A Critical Analysis" en GBERIE, L. (ed.): Rescuing a Fragile State. Sierra Leone 2002-2008, Ontario, LCMSDS Press of Wilfrid Laurier University, 2009, p. 62.

40 Johny Paul Koroma del AFRC nunca pudo ser detenido y su paradero hasta día de hoy es desconocido. Por su parte, el líder del RUF, Foday Sankoh, murió durante su detención en julio de 2003, mientras que unos meses después, en diciembre de ese año, Sam Bockarie moría en Liberia en medio de los enfrentamientos armados que afectaban a ese país por entonces. Hinga Norman también falleció antes de que se anunciara cualquier veredicto. Charles Taylor no fue detenido hasta marzo de 2006, después de estar varios años refugiado en Nigeria.

${ }^{41}$ PENFOLD, Peter, "The Special Court for Sierra Leone: A Critical Analysis" en GBERIE, L. (ed.): Rescuing a Fragile State. Sierra Leone 2002-2008, Ontario, LCMSDS Press of Wilfrid Laurier University, 2009, pp. 53-72. 
La apuesta por el despliegue del Tribunal evidenció la preponderancia de una iniciativa esencialmente exógena (aunque formalmente requerida por el gobierno sierraleonés) y en el que la participación social fue mínima, evidenciando el escaso nivel de apropiación local. La CVR, que contó con un presupuesto mucho menor que el del Tribunal, vio diezmado su mandato y su capacidad operativa una vez el Tribunal se puso en marcha. Y es que la CVR criticó en todo momento las dificultades que planteaba para sus objetivos la presencia del Tribunal, al desincentivar la declaración de importantes testimonios que tenían miedo a que sus declaraciones fueran utilizadas por éste ${ }^{42}$.

No debe tampoco idealizarse el papel de la CVR. Aunque su enfoque fue mucho más socio-céntrico que el del TPSL, la CVR no logró ni el impacto deseado (las reparaciones sugeridas no fueron en buena medida implementadas) ni tampoco tuvo la capacidad de incorporar iniciativas de reconciliación verdaderamente locales que, de manera espontánea, ya se estaban impulsando en muchas comunidades (como fue el caso paradigmático de las llamadas 'Fambul tok' $)^{43}$.

No obstante, la CVR contribuyó de manera clara a impulsar un enfoque más transformador de la Justicia Transicional ${ }^{44}$. Mientras que el Tribunal estaba encaminado estrictamente a abordar los síntomas de la guerra, juzgando a los que consideró como "principales responsables de los crímenes cometidos", la CVR, en uno de sus volúmenes, establecía un exhaustivo análisis sobre las causas de la guerra, enfatizando claramente la dimensión socioeconómica y distributiva. La explotación, marginación y frustración social de una parte importante de la población, especialmente de los más jóvenes en las áreas rurales, era identificado como uno de los factores que la transición debía abordar si quería avanzar de forma efectiva hacia un escenario de paz positiva. Precisamente, la coyuntura sierraleonesa actual pone de relieve cómo el país ha avanzado hacia un modelo de paz securitizado y negativo, en el que no existe violencia armada, pero en el que los índices de pobreza, desigualdad y marginación socioeconómica siguen siendo muy elevados. Las causas de fondo que provocaron la guerra, subrayaba una de los volúmenes de la CVR, siguen intactas.

\section{Marruecos: ni transición ni justicia}

Tras el fallecimiento de Hassan II en 1999, la subida al trono de Mohamed VI fue recibida con cautela en Marruecos. El nuevo rey se presentaba como un modernista decidido a dejar atrás la sistemática represión llevada a cabo desde la independencia, y en especial por su padre durante los llamados 'años de plomo' o 'años negros' (1961-1990). La represión sistematizada se había abatido contra opositores, militantes de izquierdas, sindicalistas, feministas o saharauis y rifeños, pero también contra militares tras los intentos de golpe

42 SESSAY, A., C. UKEJE, O. GBLA y O. ISMAIL, op. cit., 2009

${ }^{43}$ El Fambul Tok ("conversación familiar" en lengua krio) es una tradición con una larga historia anterior a la guerra en Sierra Leona. Esta práctica se basa en la explicación de los acontecimientos ante el conjunto de la comunidad.

${ }^{44}$ GREADY, Paul y ROBINS, Simon, "From transitional to transformative justice: A new Agenda for practice", International Journal of Transitional Justice, vol. 8, 2014, pp. 339-361. 
de estado de 1971 y $1973^{45}$. Miles de personas, unas 60.000 según algunas estimaciones ${ }^{46}$, habían sido detenidas o desaparecidas, torturadas y sometidas a tratos degradantes.

El nuevo rey Mohamed VI inauguró en enero de 2004 la Instancia de Equidad y Reconciliación (IER) ${ }^{47}$, inspirada en el modelo sudafricano de Comisión de la Verdad: el primer mecanismo explícito de Justicia Transicional en todo el Mundo Árabe. La IER adquirió el mandato de investigar los casos de detención arbitraria y desapariciones forzosas, casos de tortura, ejecuciones extrajudiciales, uso excesivo de la fuerza contra manifestantes, violencia sexual y exilio forzoso, ocurridas desde la independencia del país en 1956 hasta el final del reinado de Hassan II en 1999.

La propuesta formal en 2003 hecha al rey por parte de la Comisión Consultiva de Derechos Humanos (CCDH) expresaba los objetivos de profundizar en la transición democrática y pasar la página del pasado. El rey, en su discurso de inauguración, invistió a la nueva IER de trascendencia histórica, y la identificó como una Comisión de Verdad, Equidad y Reconciliación ${ }^{48}$. El discurso fue, sin embargo, el único momento en el que se nombró el término 'verdad', que no había sido incluido ni en la demanda de creación de la comisión por parte del CCDH ni en el nombre final de esta ${ }^{49}$. Nacía así un proyecto de reconciliación nacional con limitaciones importantes.

La IER se compuso de 17 miembros, la mitad de ellos ex-presos políticos o represaliados de la era hasaniana, antiguos militantes de la organización de víctimas Foro Marroquí por la Verdad y la Justicia (FMVJ). De hecho, pese a que la creación de la IER se publicitó como una iniciativa del nuevo rey, su materialización había sido el resultado de años de movilización $y$, finalmente, de un cierto diálogo ineludible entre el FMVJ, otras asociaciones de derechos humanos locales e internacionales, y el propio régimen.

Durante los 23 meses que duraron los trabajos de la IER, se examinaron 22.000 casos, según la propia comisión. Sin embargo, el equipo investigador no tenía poder de citación, y aunque todos los poderes públicos debían colaborar y abrir sus archivos a la investigación, no siempre fue así. Las obstrucciones y falta de cooperación de algunas fuerzas de seguridad y antiguos oficiales tampoco pudieron ser superadas, ni siquiera expuestas detalladamente en los informes públicos de la IER.

45 Ya desde la independencia en 1956, y durante el reinado de Mohamed $\mathrm{V}$ hubo graves violaciones de derechos humanos, en general contra toda oposición al establecimiento de un poder monárquico indiscutible. Estos primeros crímenes fueron a menudo realizados con el respaldo y participación de las ex-potencias coloniales francesas y españolas. Véase sobre los primeros años del Marruecos independiente a DALLO, Ignace, Les Trois Rois: la monarchie marocaine de l'indépendance à nos jours, Fayard, París, 2004.

${ }^{46}$ SLYOMOVICS, Susan, "Témoignages, écrits et silences: I'Instance Equité et Réconciliation (IER) marocaine et la reparation" en L'Année du Maghreb, vol. 4, 2008, pp. 123-148.

${ }^{47}$ Alta Decisión Real del 6 de noviembre de 2003, en aprobación de la recomendación adoptada por el Consejo Consultivo de Derechos Humanos, en virtud del artículo 7 del Dahir N 1.00 .350 relativo a la reorganización del Consejo.

48 CONSEIL CONSULTATIF DES DROITS DE L'HOMME, Rapport Final: Verité, Equité et Réconciliation, Instance Équité et Réconciliation, Royaume du Maroc, vol. 1, Rabat, 2009.

${ }^{49}$ LAOUINA, Marouane "L'Instance Équité et Réconciliation: Une justice transitionelle sans transition" en GOBE, Éric (dir.), Des justices en transition dans le monde arabe? Contributions à une réflexion sur les rapports entre justice et politique, Centre Jacques-Berque, Rabat, 2016, pp. 247 - 262. 
Las propuestas planteadas por la IER al final de su mandato fueron recogidas por el $\mathrm{CCDH}$, que debía encargarse de desarrollarlas. Estas incluían numerosas recomendaciones que abarcaban desde programas de reparación individual, a novedosos programas de desarrollo comunal en algunas de las regiones más marcadas por la represión ${ }^{50}$. La IER también recomendaba reformas legislativas e institucionales profundas, desde mejoras constitucionales amplias de garantías de derechos humanos hasta aspectos concretos como la abolición de la pena de muerte. Asimismo, se emplazaba al estado a adoptar el Estatuto de Roma y la jurisdicción de la Corte Penal Internacional, a la que a día de hoy aún no se ha adherido.

\subsection{Resultados ambiguos y contestados}

Como comisión de verdad que pretendía ser la IER, la instancia se dotó de dos mecanismos concretos en esta dirección. Por un lado, el trabajo de investigación de los casos de violaciones y abusos de derechos humanos presentados se tradujo en apertura de fosas comunes, en redacción de informes sin excesivo detalle, así como en reuniones y diálogo entre víctimas y la IER para informar de cada caso de manera individual. Pese a las cifras de casos resueltos publicados en informes y en la prensa, las asociaciones de víctimas y de derechos humanos siguen poniendo en duda su veracidad ya que muchos afirmaron no tener conocimiento de resultados pese a ser demandantes o víctimas. La falta de transparencia en el proceso de implementación de los resultados y de información sobre los desaparecidos y su lugar de inhumación ha sido una de las principales críticas.

Por otro lado, un mecanismo de gran importancia y relevancia fueron las audiciones públicas de testigos y víctimas acerca de las experiencias sufridas. Las audiciones de ciertos casos y en determinadas regiones fueron cubiertas con gran seguimiento en televisión. En ellas los testigos se comprometían a no mencionar los nombres, si los sabían, de sus verdugos.

La respuesta de una parte de la sociedad civil fue la organización de sesiones no oficiales de testimonio público. El 12 de febrero de 2005, la Asociación Marroquí de Derechos Humanos organizó, con poca publicidad ni cobertura mediática, una sesión de 9 testigos en las que no se censuraron los nombres de los victimarios. En la misma sesión se abordaron también crímenes de la época de Mohamed VI, contestando así también el mandato temporal de la IER ${ }^{51}$.

A la imposibilidad de mencionar a los conocidos autores directos de los abusos de derechos humanos o de las decisiones tomadas, que reforzó la sensación de impunidad del proceso, se añadió el no esclarecimiento de los casos más destacados de desaparición forzosa, sobretodo de los militantes de izquierdas Mehdi Ben Barka, Omar Benyellun o Houcine Manouzi. La inactividad de la IER en estos casos altamente emblemáticos sirvió de evidencia para muchos críticos de la falta de voluntad real de régimen de profundizar en los hechos del pasado.

\footnotetext{
${ }^{50}$ La IER recomendó la creación de proyectos de reparación colectiva en 11 comunidades y regiones que habían sido más afectada por la violencia y la represión del estado. Esta propuesta de compensación colectiva y el desarrollo de una serie de medidas encaminadas a promover el desarrollo económico y social en las regiones, en concreto aquellas donde existieron campos de detención secreta, no se ha desplegado aún plenamente sobre el terreno.

51 SLYOMOVICS, Susan, "Témoignages...", op.cit., par. 11.
} 
El grueso importante del trabajo de la IER se tradujo en miles de reparaciones pecuniarias por el daño causado, pero también restitución o reparaciones suplementarias. Muchos pudieron recuperar sus puestos de trabajo como enseñantes de educación pública o funcionarios de otro tipo. Se otorgó además la cobertura médica especial a muchas de las víctimas $^{52}$. La arbitrariedad y opacidad de las compensaciones y su relación con los crímenes en cada caso hacen difícil cuantificar y analizar estas informaciones, pero evidencian carencias importantes a la dimensión retributiva, suplidas con meras recomendaciones programáticas y de reformas institucionales.

En lo que a las garantías de no-repetición, la IER realizó un trabajo de recomendación de cambios legislativos y de armonización penal para permitir un verdadero acceso a los estándares internacionales de derechos humanos ${ }^{53}$. Estas reformas no se han realizado. Una década más tarde no se puede aún hablar de una verdadera independencia de la justicia ${ }^{54}$ ni de un cambio real en el uso de la fuerza por parte del estado. De hecho, la superficialidad del proceso se ha puesto de manifiesto con los casos de torturas sistemáticas contra salafíes detenidos, amparadas bajo el discurso securitario anti-terrorista, o más recientemente con las protestas contra el centro de detención y tortura ilegal en Temara o de los macro-juicios a los activistas rifeños de Hirak ${ }^{55}$.

\subsection{El discurso modernista y la Justicia Transicional}

Aunque existe un consenso generalizado en considerar el caso marroquí como un ejemplo de liberalización 'top-down', los dilemas que plantea la experiencia de la IER nos son útiles des del punto de vista del avance en el estudio y la praxis de la Justicia Transicional.

En primer lugar, igual que la duda que plantea otorgar la etiqueta de Justicia Transicional a la experiencia marroquí, politólogos e historiadores han sido cautos en situar el reino de Mohamed VI en un proceso de transición ${ }^{56}$. La dificultad de situar la IER en una verdadera transición es esclarecedora ya que, como afirma Vairel, el poder marroquí ha demostrado un experto manejo del lenguaje de la transitología ${ }^{57}$.

La pregunta que surge entonces es si es posible una justicia sin transición, en la que no hay cambios en las estructuras de poder, o una transición sin justicia, en cuanto las reformas

52 DEMATHIEU, Delphine y EUZIÈRE, Paul "L'expérience De L'instance Equité Et Réconciliation Au Maroc Entretien Avec Naima Benwakrim" en Recherches internationales, n 77, vol. 3, 2006, pp. 81-86.

53 Ibídem.

54 "En Marruecos, 10 años después de que la histórica Comisión de la Verdad y la Igualdad informara de décadas de violaciones graves de derechos humanos, la política estatal continuó protegiendo firmemente de la justicia a Ios responsables." AMNESTY INTERNATIONAL Rapport 2016/17: La situation des droits humains dans le monde, 22 de febrero de 2017, Nº d'index: POL 10/4800/2017, pp. 301-304.

55 En octubre de 2016 murió un joven aplastado por la compactadora de un camión de basura que estaba destruyendo su pescado de mercado negro confiscado por la policía. La muerte de M. Fikri desencadenó un movimiento popular en el Rif, norte de Marruecos, del cual en la actualidad hay más de 340 activistas detenidos, y algunos ya han sido sentenciados a penas de 20 años. Las condiciones de detención, de emprisionamiento y enjuiciamiento, así como el acoso a los abogados defensores han sido motivo de denuncia de las organizaciones de derechos humanos. Ver AMNESTY INTERNATIONAL, Acción Urgente: Manifestantes Rifeños Sufren Represalias Bajo Custodia, AU: 229/7 Índice: MDE 29/7208/2017, Marruecos, Fecha de emisión: 4 de octubre de 2017.

56 FELIU MARTINEZ, Laura y PAREJO, Ma Angustias "Morocco: the reinvention of a totalitarian system" en F. Izquierdo (ed.), Political Regimes in the Arab World, Routledge, Londres, 2013.

57 VAIREL, Frédéric, "La transitologie, langage du pouvoir au Maroc" en Politix, vol. 4, nº 80, 2007, pp. 109-128. 
son progresivas y hechas desde arriba, cuando los mecanismos refuerzan la impunidad de los victimarios y del régimen en el que se sustentaban, eludiendo cualquier responsabilidad individual o del estado. El secretario general de la Comisión Nacional de Derechos Humanos (heredera de la $\mathrm{CCDH}$ ), Mohamed Essabar, antiguo militante de izquierdas y de derechos humanos, no ve contradicción en ello. Essabar destaca la singularidad de llevar a cabo un proceso similar para gestionar las violaciones de derechos humanos en el marco del mismo sistema político y constitucional ${ }^{58}$. Pero, ¿es necesario para ello una justicia extraordinaria? ¿O evidencia precisamente esta política ad-hoc una voluntad de controlar y contener en todo momento el proceso sin que contagie el resto de estructuras políticas, judiciales y económicas del sistema?

Con los años, las mínimas reformas encaminadas a crear garantías de no-repetición no surgen en Marruecos de la IER ni del mandato recogido por la CNDH sino que siguen supeditadas a la voluntad real, y al fin y al cabo a la presión de las movilizaciones proderechos humanos. Con ello, parece más bien que la JT ha sido utilizada para dotar de significado transicional a lo que en realidad vendría más bien a ser una 'justicia sucesorial' en un contexto de continuidad ${ }^{59}$. El caso marroquí refuerza las críticas al mismo concepto JT mencionadas anteriormente, y expone también la creación de toda una industria de expertos que en realidad no aporta ni 'buenas prácticas' ni herramientas útiles para lidiar en profundidad con el pasado para transformar el futuro.

En segundo lugar, una cuestión importante que se plantea es las implicaciones que tiene la retribución pecuniaria como principal forma de reparación hacia los supervivientes ${ }^{60}$. Este excesivo protagonismo de la retribución en el discurso y la práctica de la Justicia Transicional entronca directamente con la narrativa de la paz liberal, en coherencia con la estrategia desarrollista del régimen y su construcción de una imagen moderna, de estabilidad y estado responsable frente a la comunidad internacional.

En tercer lugar, el caso marroquí plantea un proyecto dentro de un proceso ya iniciado de normalización, incluso oficialización del discurso de derechos humanos con un claro objetivo de legitimización y refuerzo del nuevo reinado, tanto interna como externamente. Prueba de esa reconciliación-cooptación se consiguió con la inserción en las propias instancias de derechos humanos oficiales, tanto la IER como el $\mathrm{CCDH}$, de víctimas de la represión de Hasan II.

La propuesta de la IER es así una propuesta de reconciliación impuesta, dirigida a afianzar un proyecto nuevo y modernista ideado por el nuevo rey y a su vez cooptar el discurso de derechos humanos impulsado por la sociedad civil ${ }^{61}$. Esta apropiación del discurso

\footnotetext{
${ }^{58}$ ESABBAR, Mohamed, Presidente de la CNDH. Publicado por International Coalition of Sites of Conscience "Transitional Justice in Morocco - Global Initiative for Justice, Truth and Reconciliation", 15 de febrero, 2017: https://www.youtube.com/watch?v=5Y1hE-TN-ic [Consultado el 3 de octubre de 2017]

59 LAOUINA, Marouane "L'Instance ...", op.cit.

60 SLYOMOVICS, Susan, "Témoignages...", op.cit., par. 10.

${ }^{61}$ La estrategia de cooptación del discurso de derechos humanos ya se inició en la última década de reinado de Hasan II, tal y como describe FELIU, Laura, Els Drets humans al Marroc: un instrument polític més enllà de tota ética, Centre d’Estudis sobre la Pau i el Desarmament, Bellaterra, 1994.
} 
de derechos humanos se enmarca en lo que Bayart llamaría una 'descompresión autoritaria'62, surgida por un lado de la movilización de las víctimas y de la sociedad civil, que no de la oposición política, y por otro de la necesidad del nuevo rey de distanciarse del legado hasaniano para "construir su propia legitimidad [...] sin no obstante dañar totalmente el legado de su padre, del que surge en buena parte su legitimidad y su poder"63.

En ese sentido, el caso marroquí nos presenta una serie de instrumentos para gestionar el pasado diseñados desde arriba y con la cooptación de personalidades de renombre entre los antiguos presos políticos. Ello le dio una legitimidad al proceso y una apariencia de 'apropiación de la población'. Por consiguiente, se podría adoptar la terminología que Rodrigo Uprimny y Maria Paula Saffon acuñaban para el caso colombiano: Justicia Transicional manipulativa, que tiene como objetivo asegurar la impunidad, frente a verdaderos procesos que tienen como objetivo la transformación de las relaciones de poder ${ }^{64}$.

\section{Colombia: una Justicia Transicional sin justicia o la JT como pretexto para impedir el cambio social}

Colombia ha vivido en medio de un conflicto armado por más de sesenta años. Pero la violencia forma parte integral de la historia de este país. El surgimiento de la República estuvo marcado por la violencia y las guerras. En el siglo XIX fue muy común que los partidarios de los diferentes bandos, liberales y conservadores, federalistas y centralistas, usaran sus ejércitos para imponerse por la vía de la fuerza a sus adversarios ${ }^{65}$. Al final de los conflictos era muy común que los gobernantes otorgaran la amnistía a sus antiguos enemigos, garantizándoles algo de participación política. Las Constituciones reflejaban ese acuerdo político y por ello dentro de ellas se incluía el nuevo balance de fuerzas y el nuevo arreglo entre los oponentes. La constitución era la materialización misma de los acuerdos de paz, que era escrita con la "gramática de la guerra"66.

El perdón jurídico institucionalizado era la forma en que los gobiernos tramitaban la entrega de armas por parte de los rebeldes. El pasado no era abordado, sino que la mirada recaía solamente en el futuro. Es por ello, que el modelo de reforma constitucional se adaptaba mejor a los cambios que se querían realizar ${ }^{67}$. El modelo de amnistías caracterizó a los cambios políticos colombianos hasta la década de los noventa. Sin embargo, no podemos afirmar que en Colombia se haya dado una transición política en el sentido sostenido por la literatura sobre transiciones a la democracia. Los gobiernos siguieron siendo los mismos y los únicos cambios fueron la apertura del sistema político para que los antiguos rebeldes

62 BAYART, Jean François, "La problématique de la démocratie en Afrique: La Baule et puis après ?" en Politique africaine, $\mathrm{n}^{\circ} 43,1991$, pp. 5-20.

${ }^{63}$ En el original: « ....besoin de se démarquer du règne de son père et de construire sa propre légitimité [...], sans pour autant nuire totalement au legs de son père, dont il tire en partie sa légitimité et son pouvoir. » LAOUINA, Marouane "L'Instance ...", op.cit. par. 39.

${ }^{64}$ BELL, Christine, "Transitional Justice, Interdisciplinarity and the State of the 'Field' or 'Non-Field'" en The International Journal of Transitional Justice, Vol. 3, 2009, p. 23.

65 OROzCO, Ivan, Combatientes, rebeldes y terroristas, Temis, Bogotá, 1992. PALACIOS, Marco, y SAFFORD, Frank, Colombia Pais Fragmentado, Sociedad Divida, Norma, Bogotá, 2002.

${ }^{66}$ VALENCIA VILLA, Hernando, Cartas de Batalla - Una crítica del constitucionalismo colombiano, Universidad Nacional de Colombia, Bogotá, 1987.

${ }^{67}$ ACKERMAN, Bruce, The Future of Liberal Revolution, Yale University Press, New Haven, 1994. 
pudieran tomar parte en la vida política del país. En algún momento el modelo terminó siendo extendido a las políticas contra el narcotráfico, de modo que fue muy común ver cómo los narcotraficantes eran tratados como delincuentes políticos y por tanto recibían un tratamiento privilegiado, propio del delito político ${ }^{68}$.

\subsection{La irrupción de la JT como mecanismo normativo de justicia}

El modelo de amnistías entró en crisis con el proceso de desmovilización de los paramilitares en el año 2002. Álvaro Uribe (2002-2010) llegó a la presidencia sosteniendo una agenda de lucha contra las FARC y de resolución violenta del conflicto armado. A quienes proponían negociaciones de paz se les llamaba Caguaneros, por referencia a la región en donde se dio el proceso de paz con las FARC bajo el gobierno de Pastrana (1998 - 2002) y que tuvo un final abrupto debido al hecho que los dos adversarios lo usaron como un medio para fortalecer sus posiciones en el marco del conflicto armado69.

Una vez comienzan las negociaciones para que se desmovilicen los grupos paramilitares el gobierno nacional presenta un proyecto de Alternatividad Penal, según el cual los miembros de estos grupos ilegales se someten al proceso y dejan las armas a cambio de una pena alternativa a la privación de la libertad. Este proyecto encontró pocos apoyos, pues constituía una clara vulneración a las obligaciones que tenía el Estado de investigar y sancionar las graves violaciones a los derechos humanos. Como consecuencia de este proceso empieza a hablarse de Justicia Transicional en el país y de las diferentes modalidades de Justicia Transicional para hacer frente a estas violaciones a los derechos humanos.

De manera espectacular se incrementa el número de publicaciones sobre el tema y se hace evidente el surgimiento de una industria de la Justicia Transicional, en donde las ONG de derechos humanos se ven en la necesidad de incluir dentro de sus agendas a la JT como consecuencia de la relevancia asignada a la misma por las agencias de cooperación internacional ${ }^{70}$. Sin embargo, las ONG de derechos humanos aún conservan un discurso de lucha contra la impunidad y denuncian los intentos del gobierno colombiano de garantizar una paz con perdón y olvido a los paramilitares. En esta época se escriben diversos textos de Justicia Transicional y en ellos se puede ver un mensaje coincidente de garantizar el trabajo efectivo de la justicia penal para proteger el derecho de las víctimas a la verdad, la justicia y la reparación. Incluso se habla de los usos y abusos de la JT para denunciar que bajo el manto de la JT se podrían incluir políticas de impunidad ${ }^{71}$.

El primer modelo de JT que se aplicó en Colombia se caracterizó por su impronta liberal y por el hecho de afirmar la necesidad de aplicar este tipo de mecanismos en casos de ausencia de transición ${ }^{72}$. La ley 975 de 2005 introdujo un modelo dividido en dos grandes

68 OROZCO, Ivan, Combatientes... op. cit.

69 BENAVIDES, Farid, y OSPINA, Ana María, El largo camino hacia la paz, Gustavo Ibañez, Bogotá, 2013. PIZARRO, Eduardo, Cambiar el futuro. Historia de los procesos de paz en Colombia (1981 - 2016), Debate, Bogotá, 2017.

70 MADLINGOZI, Tshepo, "On transitional justice entrepreneurs and the production of victims" en Journal of Human Rights Practice, vol. 2, n 2, 2010, pp. 175-228.

71 UPRIMNY, Rodrigo, et al., ¿Justicia Transicional sin transición? Verdad, justicia y reparación para Colombia, Dejusticia, Bogotá, 2006.

72 Ibídem. 
bloques: por una parte la verdad y la justicia se le encargaba a un sistema de justicia penal especial que debía investigar a quienes hubieran sido postulados por el gobierno nacional; y la cuestión de la reparación y de la memoria se encargaban a una institución, la Comisión Nacional de Reparación y Reconciliación, que pronto se reveló como una institución inútil, con la única salvedad del Grupo de Memoria Histórica, que operó como una suerte de think tank del conflicto armado colombiano ${ }^{73}$.

La cuestión de la reparación generó las primeras crisis en el modelo colombiano. Ante la ausencia de una verdadera transición, lo cierto es que las transformaciones que se hicieron fueron pocas y todo se centró en lo que pudiera hacer la judicatura. No hubo reformas institucionales, ni depuración de las instituciones, ni comisión de la verdad. Las pocas instituciones que se eliminaron, como el Departamento Administrativo de Seguridad DAS, lo fueron como parte de un discurso de modernización de la administración pública, pero no dentro de uno de respeto e implementación de los derechos humanos.

La primera sentencia del modelo de Justicia y Paz, la de Mampujan en contra de alias Juancho Dique y de alias Julián Bolivar (CSJ 27 de abril de 2011) ${ }^{74}$, otorgó una reparación importante para las víctimas, lo cual generó preocupación en el gobierno nacional, pues si se aplicara este estándar a todas las víctimas, debería usarse el presupuesto nacional de al menos diez años para poder pagar todas las indemnizaciones. Por esa razón el gobierno administrativizó la reparación, lo que la hizo un poco más lenta y, sobre todo, permitió controlar el monto de lo pagado a las víctimas. Al lado de ello se aprobó la ley de víctimas y de restitución de tierras, ley 1448 de 2011, que estableció un sistema de justicia especial y un procedimiento especial para la restitución de tierras a las víctimas, lo que ha sido llamado la Justicia Transicional civil75. Pese a las bondades de la ley de víctimas, el modelo de Justicia Transicional elaborado para enfrentar el pasado de violencia paramilitar no produjo transformaciones radicales en el Estado colombiano, ni supuso una redistribución de la tierra. Todo lo contrario. En muchos casos las víctimas recuperaron su tierra para simplemente ver cómo eran despojadas de ellas de nuevo ${ }^{76}$. Las garantías de no repetición no se cumplieron y se hizo evidente las limitaciones de un concepto como el de Justicia Transicional sin transición. En otras palabras, los mecanismos implementados por el gobierno colombiano no contribuyeron a un mejor acceso a la tierra y no han contribuido a la eliminación de las violencias en el país. Los activistas de derechos humanos continúan siendo objeto de ataques y el Estado colombiano se manifiesta incapaz de lidiar con las diversas formas de violencia. ${ }^{77}$

73 BENAVIDES, Farid, y OSPINA, Ana María, El largo camino..., op.cit.

${ }^{74}$ El 10 de marzo del 2000, el bloque Montes de María de los paramilitares asesinó a once campesinos y desplazó a 1.100 personas en la vereda de Mampuján, a dos horas de la ciudad de Cartagena de Indias. El Tribunal de Justicia y Paz de Bogotá, creado dentro del proceso de Justicia Transicional para los grupos paramilitares, condenó a los ex jefes paramilitares 'Diego Vecino' y 'Juancho Dique' a ocho años de cárcel y pidió la reparación de las víctimas. La Corte Suprema ratificó el fallo y ordenó que para abril de 2012, las víctimas debían ser indemnizadas. De acuerdo con la Unidad de Víctimas, a marzo de 2017 se había cumplido con un $90 \%$ de lo ordenado por el Tribunal. Ver http://www.unidadvictimas.gov.co/en/node/33849 última visita 8 de noviembre de 2017.

75 SÁNCHEZ, Nelson Camilo, Tierra en transición: Justicia Transicional, restitución de tierras y política agraria en Colombia, Dejusticia, Bogotá, 2017.

${ }^{76}$ MONCADA, Patrica, y BUITRAGO, Natali, "Los opositores en el proceso de restitución de tierras: análisis cuantitativo de la jurisprudencia, 2012-2014" en Revista Derecho Público, no 33, 2014, pp. 590 - 623.

77 HUMAN RIGHTS WATCH. "Defensores en Riesgo". 24 de abril de 2017. En https://www.hrw.org/es/ news/2017/04/24/colombia-defensores-en-riesgo . Última visita 4 de junio de 2018. Es claro que la reforma 


\subsection{La JT como mecanismo para una justicia degradada}

El proceso de paz con las FARC generó una dinámica diferente a aquel con los paramilitares. La cuestión de la justicia penal comenzó a ser discutida y se intentó construir un modelo en el que la privación de la libertad no fuera el eje central. En un primer momento el gobierno nacional intentó constitucionalizar algunas de las medidas de Justicia Transicional, pero estas fueron rechazadas por las FARC, por lo que el denominado Marco Jurídico para la Paz, aprobado en el año 2012 tuvo escasa aplicación. Los acuerdos de paz de 2016 introdujeron un modelo complejo, a veces confuso, de Justicia Transicional dividido en varios niveles. Por una parte, se busca que haya una relativa distribución de la tierra, con una reforma agraria. Se garantiza la participación política de los miembros de las FARC. En materia de responsabilidad por un pasado de violaciones a los derechos humanos se introduce la Comisión de Esclarecimiento de la Verdad, encargada de elaborar un relato sobre el pasado de violaciones a los derechos humanos. Al lado de ello se crea un sistema de justicia penal especial en varios niveles, el cual se encarga de aplicar penas restrictivas de la libertad a quienes contribuyan a la verdad y la reparación y penas leves para quienes hayan cometido crímenes graves y penas de hasta 20 años de prisión para quienes no contribuyan al proceso de Justicia Transicional.

El nuevo sistema ha sido objeto de críticas porque se considera que otorga beneficios muy amplios a los ex guerrilleros de las FARC. Sin embargo, esto se justifica dentro del marco de tratamiento benigno del delincuente político, esto es, el rebelde que se enfrenta al Estado con una finalidad altruista ${ }^{78}$. Pero no se dice nada del tratamiento dado a los militares, a quienes se les quiere incluir en estas políticas benignas sin que se aclare cuál sería su contribución a la justicia y a la reparación. Es pronto para evaluar el sistema resultante del proceso de paz con las FARC, pero sí es claro que un año después de los acuerdos los asesinatos de líderes sociales continúan, más de 30 guerrilleros desmovilizados han sido asesinados, surgen nuevos ejércitos, la restitución de tierras no se ha dado, y en general la mayor parte de los acuerdos no ha sido implementada. En noviembre del 2017 el Instituto Kroc hablaba del cumplimiento de apenas $17 \%$ de los acuerdos, lo que de manera optimista presentaban como el vaso medio lleno, pese al hecho que la mayor parte de ese cumplimiento se refería a la desmovilización y desarme de las FARC. ${ }^{79}$

El discurso de la Justicia Transicional en Colombia ha servido para justificar una serie de medidas que garantizan la impunidad e impiden el cambio social. La idea de una Justicia Transicional sin transición pasa por alto que estos mecanismos buscan garantizar que haya justicia durante la transición y que uno de los objetivos es el fortalecimiento del estado de derecho. La ausencia de políticas redistributivas nos muestra la necesidad de aplicar medidas fuera de la caja de herramientas de la Justicia Transicional para garantizar la justicia social. En el caso colombiano se observa que la aplicación de medidas de Justicia Transicional ha sido un obstáculo más que un incentivo para garantizar la visión de la justicia contenida en la

agraria y una mayor igualdad para la población no es posible dentro de un contexto de violencia estructural. Pero precisamente una de las promesas de la JT es que la reforma de corte liberal creará las condiciones para que ello sea posible. En este texto mostramos que esa promesa es irreal e imposible de cumplir con la simple aplicación de los mecanismos de la JT y de una paz liberal.

78 OROZCO, Iván, Combatientes, rebeldes y terroristas, Temis, Bogotá, 1992. OROZCO, Iván. Justicia Transicional en tiempos del deber de memoria. Universidad de los Andes, Bogotá, 2009.

${ }^{79}$ Informe Instituto Kroc. Noviembre 2017. En https://reliefweb.int/report/colombia/informe-sobre-el-estadoefectivo-de-implementaci-n-del-acuerdo-de-paz-en-colombia . Última visita 4 de junio de 2018. 
Constitución Política de 1991, una de un Estado Social y Democrático de Derecho.

\section{Conclusiones}

En este texto hemos analizado algunos de los principales límites de la Justicia Transicional. Su matriz liberal hace difícil que la aplicación de mecanismos de JT conduzca a una verdadera transformación estructural de las sociedades en las que interviene como se ha pretendido a menudo, no sólo en cuanto al componente de justicia (estructuras de impunidad), sino en cuanto a la transformación de las estructuras de exclusión social y de vulnerabilidades para evitar que las personas sean víctimas de violaciones de sus derechos.

El modelo liberal de la JT no tiene en cuenta el contexto en el cual se deben aplicar los mecanismos y por ello carece de una verdadera apropiación y participación local. Esto no quiere decir que no existan formas de enfrentar el pasado en las comunidades, sino que estas formas no encajan fácilmente en el modelo exógeno y estandarizado que acaba implementando la llamada "industria de la Justicia Transicional". Esto genera tensiones entre los actores locales e internacionales y lleva a una devaluación de las formas genuinas de enfrentar al pasado.

Es preciso por ello reforzar los mecanismos de apropiación local de estos procesos y tener en cuenta formas de JT desde abajo, en donde se reconozcan las formas locales de hacer justicia, de alcanzar la reconciliación y de averiguar la verdad del pasado. Pero todo ello evitando que lo local sirva como excusa para no hacer justicia o para ocultar el pasado y, en todo caso, debe tenerse en cuenta el riesgo de que las formas locales de justicia vulneren derechos fundamentales. El caso de Sierra Leona nos muestra que una mayor apropiación y diálogo es necesario para evitar que las iniciativas más verticales y de carácter exógeno acaben minando los esfuerzos de JT más enraizados en las visiones locales y en un análisis de las causas de fondo a transformar. Asimismo, los casos colombiano y marroquí advierten de los riesgos de cooptar la agenda de los movimientos de derechos humanos en función de lo que piden las agencias de cooperación en materia de JT o de cooptación de los propios actores del movimiento, con lo que a menudo no se consigue mayor justicia sino la burocratización, desmovilización y división del movimiento por la defensa de los derechos humanos.

Uno de los riesgos también señalados es la securitización de la transición, apuntalada en una mirada esencialmente estado-céntrica de la JT. Una mirada socio-céntrica, desde las organizaciones de derechos humanos y de las propias víctimas se convierte, en este sentido, en algo ineludible. Y es que la actual retórica de la JT está obstaculizando cambios significativos en las relaciones de poder, generando apariencia de cambio y legitimando la continuidad. Es fundamental, por lo tanto, abandonar un modelo de Justicia Transicional sin transición, pues los mecanismos propios de la JT solo tienen vocación transformadora en un verdadero contexto de transición. La JT debe ser entendida como un proceso que avanza de forma paulatina y cuyo objetivo principal es la transformación de las relaciones desiguales de poder y las causas que generan exclusión y marginación. La no repetición de los hechos sólo se logra mediante el fortalecimiento de la justicia y de la emancipación social.

Es importante preguntarse, finalmente, si la JT nos permite alcanzar esos objetivos o si, por el contrario, es necesario adoptar visiones mucho más transformadoras de la 
sociedad. El presente artículo ha pretendido abrir nuevos espacios de investigación sobre la vocación transformadora de la JT y, sobre todo, sobre formas de justicia que conduzcan a la eliminación real de las estructuras de impunidad y a la construcción de sociedades más justas e incluyentes.

Hace varios años Posner y Vermeule concluyeron que a la JT se le pedían resultados que no se le pedían a la justicia ordinaria ${ }^{80}$. El problema, en nuestra opinión, es que la caja de herramientas liberal de la JT hace esas promesas, pero evita implementar las transformaciones necesarias para ello. Los casos de Sierra Leona y de Marruecos constituyen lecciones importantes para el caso colombiano en el sentido de destacar la necesidad de transformaciones estructurales para poder alcanzar los fines de la JT. Por ello creemos que una justicia transformadora es imposible dentro de los estrictos marcos de la JT y por tanto creemos que más que una mejor Justicia Transicional es necesario buscar algo mejor que la Justicia Transicional.

\section{Bibliografía}

ACKERMAN, Bruce, The Future of Liberal Revolution, Yale University Press, New Haven, 1994.

ALFONSÍN, Raúl, Memoria Politica: Transicion a la Democracia y Derechos Humanos, Fondo de Cultura Económica, Buenos Aires, 2004.

AMNESTY INTERNATIONAL, Rapport 2016/17: La situation des droits humains dans le monde, 22 de febrero de 2017, n d>index: POL 10/4800/2017, pp. 301-304.

AMNESTY INTERNATIONAL, Acción Urgente: Manifestantes Rifeños Sufren Represalias Bajo Custodia, AU: 229/7 Índice: MDE 29/7208/2017, Marruecos, Fecha de emisión: 4 de octubre de 2017.

ARTHUR, Paige, "How 'Transitions' Reshaped Human Rights: A Conceptual History of Transitional Justice", Human Rights Quarterly, n³1, 2009, pp. 321 - 367.

ASH, Timothy Garton, "The Truth About Dictatorship", The New York Review of Books, 1998.

ASWAB, Mohamed "Le Forum Vérité et Justice accuse le CCDH de laxisme" en Aujourd'hui, 26 de febrero de 2010: http://aujourdhui.ma/focus/le-forum-verite-et-justice-accuse-le-ccdh-delaxisme-69248 [Consultado el 30 de agosto de 2017]

BAYART, Jean François, "La problématique de la démocratie en Afrique: La Baule et puis après ?" en Politique africaine, $\mathrm{n}^{\circ} 43,1991$, pp. 5-20.

BELL, Christine, "Transitional Justice, Interdisciplinarity and the State of the 'Field' or 'Non-Field'" en The International Journal of Transitional Justice, vol. 3, 2009, pp. 5-27.

BENAVIDES, Farid, y OSPINA, Ana María, El largo camino hacia la paz, Gustavo Ibañez, Bogotá, 2013.

BOURDIEU, Pierre y TEUBNER, Gunther, La fuerza del derecho, Universidad de los Andes, Bogotá, 2000.

BOURDIEU, Pierre, Outline of a Theory of Practice, Cambridge University Press, Cambridge, 2005.

CESPEDEZ BAEZ, Lina María, Utopía u oportunidad fallida. Análisis crítico del acuerdo de paz, Universidad del Rosario, Bogotá, 2017.

CESPEDES BAEZ, Lina María, "Creole radical feminist transitional justice. An exploration of Colombian feminism in the context of armed conflict" en Fabio Andrés Díaz Pabón, Truth, Justice and Reconciliation in Colombia. Transitioning from Violence, Routlegde, Londres, 2018.

CONSEIL CONSULTATIF DES DROITS DE L'HOMME, Rapport Final: Verité, Equité et Réconciliation, Instance Équité et Réconciliation, Royaume du Maroc, vol.1., Rabat, 2009.

CRAMER, Christopher, Civil War is not a Stupid Thing. Accounting for Violence in Developing Countries, Londres, Hurst y Company, 2006.

CSJ, "Sentencia condenatoria contra Edwar Cobos Téllez y Uber Enrique Banque Martínez", Bogotá, 27 de abril de 2011.

DALLO, Ignace, Les Trois Rois: la monarchie marocaine de l'indépendance à nos jours, Fayard, París, 2004.

D'COSTA, Bina, "Of impunity, scandals and contempt: chronicles of the justice conundrum" en International Journal of Transitional Justice, no 9, 2015, pp. $357-366$.

DEMATHIEU, Delphine y EUZIÈRE, Paul, "L'expérience De L'instance Équité Et Réconciliation Au Maroc Entretien Avec Naima Benwakrim" en Recherches internationales, n 77, vol. 3, 2006, pp. 81-

${ }^{80}$ POSNER, Eric, y VERMEULE, Adrian, "Transitional Justice..." Op. cit. 
86.

DIEHL, Paul y Daniel DRUCKMAN. Evaluating Peace operations, Londres, Lynee Rienner Publishers, 2010.

DOUGHERTY, Beth K., "Searching for Answers: Sierra Leone's Truth y Reconciliation Commission" en African Studies Quarterly, vol. 8, no 1, 2004.

DUBE, Siphiwe Ignatius, "Transitional justice beyond the normative: towards a literary theory of political transitions" en International Journal of Transitional Justice, n05, 2011, pp. 177 - 197.

DUGAL, Z., "Witness to Truth: the TRC of Sierra Leone - An Overview" en GBERIE, L. (ed.), Rescuing a Fragile State. Sierra Leone 2002-2008, LCMSDS Press of Wilfrid Laurier University, Ontario, 2009.

ELSTER, Jon, Closing the Books: Transitional Justice in Historical Perspective, Cambridge University Press, Cambridge, 2011.

ESABBAR, Mohamed, "Transitional Justice in Morocco - Global Initiative for Justice, Truth and Reconciliation", International Coalition of Sites of Conscience, 15 de febrero, 2017: https:// www.youtube.com/watch?v=5Y1hE-TN-ic [Consultado el 3 de ocutbre de 2017].

FEIERSTEIN, Daniel, Juicios. Sobre la elaboración del genocidio, II, Fondo de Cultura Económica, Buenos Aires, 2015.

FELIU MARTINEZ, Laura y PAREJO, Ma Angustias "Morocco: the reinvention of a totalitarian system" en F. Izquierdo (ed.), Political Regimes in the Arab World, Routledge, Londres, 2013.

FELIU MARTINEZ, Laura y PAREJO, Ma Angustias "Nouvelles et anciennes dynamiques constitutionnelles au Maroc. Les acteurs politiques face à la reforme constitutionnelle de 2011" en SEDJARI, Ali (ed.), Pouvoir et contre-pouvoir à I'heure de la démocratie et des droits humains, L'Harmattan, París, 2014.

FIDH "La Commission Marocaine Pour La Verite : Un Premier Bilan" en Federación Internacional de Derechos Humanos, 4 de octubre de 2006. En línea: https://www.fidh.org/fr/regions/maghrebmoyen-orient/maroc/LA-COMMISSION-MAROCAINE-POUR-LA [Consultado el 30 de octubre de 2017].

FOUCAULT, Michel, Las palabras y las cosas. Una arqueología de las ciencias humanas, Siglo XXI, Madrid, 2006.

FREEMAN, Mark, Necessary Evils: Amnesties and the Search for Justice, Cambridge University Press, Cambridge, 2011.

GARGARELLA, Roberto, De la injusticia penal a la justicia social, Universidad de los Andes, Bogotá, 2008.

GONZALEZ-OCANTO, Ezequiel, Shifting Legal Visions: Judicial Change and Human Rights Trials in Latin America, Cambridge University Press, Cambridge, 2017.

GREADY, Paul y ROBINS, Simon, "From transitional to transformative justice: A new Agenda for practice" en International Journal of Transitional Justice, vol. 8, 2014, pp. 339-361.

HUMAN RIGHTS WATCH, "La commission marocaine de vérité Le devoir de mémoire honoré à une époque incertaine" en Human Rights Watch, Volumen 17, no 11, noviembre de 2005.

HUMAN RIGHTS WATCH, "Defensores en Riesgo", 24 de abril de 2017, en https://www.hrw.org/es/ news/2017/04/24/colombia-defensores-en-riesgo [Consultado el 4 de junio de 2018].

INFORME INSTITUTO KROC, noviembre 2017, en https://reliefweb.int/report/colombia/informe-sobreel-estado-efectivo-de-implementaci-n-del-acuerdo-de-paz-en-colombia, [Consultado el 4 de junio de 2018].

INTERNATIONAL CRISIS GROUP (ICG), Sierra Leone After Elections: Politics as Usual? en Africa Report, n. 49, Freetown / Bruselas, 2002.

INTERNATIONAL CRISIS GROUP (ICG), "Sierra Leone: The State of Security and Governance" en Africa Report, 67, Bruselas, 2003.

KRITZ, Neil (ed.), Transitional Justice. How emerging democracies reckon with former regimes, United States Institute for Peace, Washington, 1995.

KUHN, Thomas, The Structure of Scientific Revolutions. 50th Anniversary edition, Chicago University Press, Chicago, 2012 [Primer edición: 1962].

LABDAOUI, Abdellah, "L'IER : un transformateur politique ?" en Confluences Méditerranée, vol.3, n 62, 2007, pp. 15-24.

LAOUINA, Marouane, "L'Instance Équité et Réconciliation: Une justice transitionelle sans transition" en GOBE, Éric (dir.), Des justices en transition dans le monde arabe? Contributions à une réflexion sur les rapports entre justice et politique, Centre Jacques-Berque, Rabat, 2016, pp. 247 - 262.

LEFRANC, Sandrine, "La justice transitionnelle n'est pas un concept" en Mouvements, vol. 1, $\mathrm{n}^{\circ} 53$, 2008, pp. 61-69: www.cairn.info/revue-mouvements-2008-1-page-61.htm [Consultado el 30 de octubre de 2017].

LESSA, Francesca, "Justice beyond borders: the Operation Condor Trial and accountability for transnational crimes in South America" en International Journal of Transitional Justice, no 9, 2015, pp. 494 - 506.

LEWIS, Alison, "Confessions and the Stasi Files in PostCommunist Germany: The Modest Scales of 
Memory and Justice in Traitor to the Fatherland" en Australian Humanities Review, no 59, 2016, pp. 209-222.

LOUDIYI, Fadoua, Transitional Justice and Human Rights in Morocco: Negotiating the Years of Lead, Routledge, 2014.

MADLINGOZI, Tshepo, "On transitional justice entrepreneurs and the production of victims" en Journal of Human Rights Practice, vol. 2, no 2, 2010, pp. 175-228.

MALAN, Jannie, "Understanding Transitional Justice" en FRANCIS, David J. (ed.), Peace and conflict in Africa, Nueva York, Zed Books, 2010, pp. 133-147.

MALLINDER, Louise, Amnesty, Human Rights and Political Transitions: Bridging the Peace and Justice Divide, Hart, Londres, 2008.

MCAULIFFE, Padraig, "Transitional justice's expanding empire: reasserting the value of the paradigmatic transition" en Journal of Conflictology, vol. 2, no 2, 2011, pp. 32-44.

MENDEZ, Juan, Accountability for past abuses, Kellogg Institute, Chicago, 1996.

MICHALOWSKY, Sabine, Corporate accountability in the context of transitional justice. Routledge, Londres, 2016.

MOHSEN-FINAN, Khadija, "Mémoire et réconciliation nationale au Maroc" en Politique étrangère, vol. 2 (verano), 2007, pp. 327-338.

MOKHLISS, Brahim, "Droits de I'Homme au Maroc : A chacun son bilan..." en Le Reporter, 2007: www. yabiladi.com/article-societe-1748.html [Consultado el 28 de octubre de 2017].

MONCADA, Patrica, y BUITRAGO, Natali, "Los opositores en el proceso de restitución de tierras: análisis cuantitativo de la jurisprudencia, 2012-2014" en Revista Derecho Público, no 33, 2014, pp. 590 - 623.

MUTUA, Makau, "What is the future of transitional justice" en International Journal of Transitional Justice, no 9, 2015, pp. 1 - 9.

NAGY, Rosemary, "Transitional Justice as a Global Project" en Third World Quarterly, vol. 2, no 29, 2008, pp. 275 - 289.

NESIAH, Vasuki, Transitional justice practice: looking back, moving forward, Research Report. Impunity Watch (May, 2016).

NINO, Carlos Santiago, Juicio al mal absoluto. ¿Hasta dónde debe llegar la justicia retroactiva en casos de violaciones masivas de los derechos humanos?, Ariel, Madrid, 2006.

NO PEACE WITHOUT JUSTICE (NPWJ), "Lawyers' Guide to the Special Court for Sierra Leone", Freetown, 2004.

OLSEN, Tricia D., PAYNE, Leigh A. y Reiter, Andrew G., Transitional Justice in Balance: Comparing Processes, Weighing Efficacy, United States Institute for Peace, Washington, 2010.

ONU, "El Estado de Derecho y la Justicia de Transición en las sociedades que sufren o han sufrido conflictos", Nueva York, S/2004/616.

ONU, "Guidance note of the Secretary-General UN approach to Transitional Justice", 2010, p. 2: https:// www.un.org/ruleoflaw/files/T]_Guidance_Note_March_2010FINAL.pdf [Consultado el 06 de junio de 2018].

ONU, "Informe del Relator de Naciones Unidas sobre la Promoción de la Verdad, la justicia, la reparación y las garantías de no repetición" A/2012/67/368.

OROZCO, Ivan, Combatientes, rebeldes y terroristas, Temis, Bogotá, 1992.

OROZCO, Ivan. Justicia Transicional en tiempos del deber de memoria, Universidad de los Andes, Bogotá, 2009.

PALACIOS, Marco, y SAFFORD, Frank, Colombia Pais Fragmentado, Sociedad Divida, Norma, Bogotá, 2002.

PALMER, Nicola, CLARCK, Phil y GRANVILLE, Danielle, Critical Perspectives in Transitional Justice. Londres: Interesentia, 2012.

PENFOLD, Peter, "The Special Court for Sierra Leone: A Critical Analysis" en GBERIE, L. (ed.): Rescuing a Fragile State. Sierra Leone 2002-2008, LCMSDS Press of Wilfrid Laurier University, Ontario, 2009.

PERRAULT, Gilles. Nuestro Amigo el Rey, Plaza\&Janés/Cambio16, Barcelona, 1991.

PIZARRO, Eduardo, Cambiar el futuro. Historia de los procesos de paz en Colombia (1981 - 2016), Debate, Bogotá, 2017.

POSNER, Eric, y VERMEULE, Adrian, "Transitional Justice as Ordinary Justice" en Chicago Unbound, 2003, pp. $762-825$.

ROHT-ARRIAZA, Naomi y MARIEZCURRENA, Javier, Transitional Justice in the Twenty-First Century: Beyond Truth versus Justice, Cambridge University Press, Nueva York, 2006.

ROJAS, Gabriel, Hacia una Justicia Transicional crítica. La institución social de castigo en el Acuerdo de Paz Final entre el Gobierno Nacional y la guerrilla de las FARC-EP en Colombia, Tesis Doctoral, Universidad de los Andes, Bogotá, 2017.

SÁNCHEZ, Nelson Camilo, Tierra en transición: Justicia Transicional, restitución de tierras y política agraria en Colombia, Dejusticia, Bogotá, 2017. 
SEBTI, Abdelahad, "Instance Equité et réconciliation, dix ans après..." en Zaman, 23 de abril de 2014 : http://zamane.ma/fr/instance-equite-et-reconciliation-dix-ans-apres/ [Consultado el 29 de octubre de 2017].

SESSAY, A., C. UKEJE, O. GBLA y O. ISMAIL, Post-war regimes and State Reconstruction in Liberia and Sierra Leone, Dakar, CODESRIA, 2009.

SHARP, Dustin, "Emancipating transitional justice from the bonds of the paradigmatic transition" en International Journal of Transitional Justice. Special Issue Transitional Justice. Does it have a future?, vol. 9, n 1, 2015, pp. 150 - 169.

SLYOMOVICS, Susan, "Témoignages, écrits et silences: I'Instance Équité et Réconciliation (IER) marocaine et la reparation" en L'Année du Maghreb, vol. 4, 2008, pp. 123-148.

SRIRAM, Chandra Lekha, "Justice as Peace? Liberal Peacebuilding and Strategies of Transitional Justice" en Global Society, vol. 21, no 4, 2007, pp. 579-591.

TEITEL, Ruti, Transitional Justice, Oxford University Press, Oxford, 2000.

TEITEL, Ruti, "Transitional Justice Genealogy" en Harvard Human Rights Journal, no 16, 2003, pp. 69 - 94.

UPRIMNY, Rodrigo, SAFFON, María Paula, Botero, Catalina, y Restrepo, Esteban, ¿Justicia Transicional sin transición? Verdad, justicia y reparación para Colombia, Dejusticia, Bogotá, 2006.

VAIREL, Frédéric, "Le Maroc des années de plomb: équité et réconciliation?" en Politique africaine, vol. 4, n० 96, 2004, pp. 181-195.

VAIREL, Frédéric, "La transitologie, langage du pouvoir au Maroc" en Politix, vol. 4, no 80, 2007, pp. 109-128.

VAIREL, Frédéric, "Qu'avez-vous fait de vos vingt ans?: Militantismes marocains du 23-mars (1965) au 20 février (2011)" en L'Année du Maghreb, VIII, 2012, pp. 219-238.

VALENCIA VILLA, Hernando, Cartas de Batalla - Una crítica del contitucionalismo colombiano, Universidad Nacional de Colombia, Bogotá, 1987.

WILCOX, Luke. "Reshaping Civil Society through a Truth Commission: Human Rights in Morocco's Process of Political Reform" en The International Journal of Transitional Justice, vol. 3, 2009, pp. 49-68. 


\section{RELACIONES INTERNACIONALES}

Revista académica cuatrimestral de publicación electrónica Grupo de Estudios de Relaciones Internacionales (GERI) Universidad Autónoma de Madrid, España

www.relacionesinternacionales.info

ISSN 1699 - 3950

ff facebook.com/RelacionesInternacionales

twitter.com/RRInternacional 